\title{
Desafios do diretor escolar na educação integral: uma inuestigação em Rondônia
}

\author{
School director's challenges at full-time education: an investigation \\ in state of rondônia
}

\section{Retos del director de escuela en educación integral: una investigación en rondônia}

\author{
Maria das Graças de Souza' \\ Faculdade Sapiens, Professora. \\ https://orcid.org/0000-0002-2975-6050 \\ Rafael Fonseca de Castro ${ }^{2}$ \\ Universidade Federal de Rondônia, Mestrado Profissional em Saúde da Família, \\ Departamento de Ciências da Educação, Programa de Pós-Graduação em Educação, \\ Professor Adjunto. \\ https://orcid.org/0000-0001-5897-851X
}

Resumo: Este estudo é resultante de uma pesquisa descritiva, de abordagem qualitativa, recorte de uma Dissertação de Mestrado. A investigação objetivou analisar, na concepção do Diretor Escolar, de que forma tem lidado com a gestão de pessoas no âmbito escolar para o alcance de metas e objetivos no contexto da educação integral. Perguntamo-nos: quais desafios relacionados à gestão de pessoas são enfrentados pelo Diretor Escolar? Os dados foram coletados por meio de entrevista sendo os sujeitos participantes dois diretores que atuam em escolas que ofertam Ensino Médio em Tempo Integral de dois municípios do estado de Rondônia, Amazônia Ocidental brasileira. Os dados foram submetidos à análise de conteúdo e são apresentados, neste artigo, resultados da categoria de análise definida a priori "Desafios da gestão de pessoas no contexto das Escolas de Ensino Médio em Tempo Integral". A pesquisa constatou o uso de um modelo padrão de gestão baseado no compromisso com a integralidade da ação educativa e que ambas as escolas estão passando por processos de mudança no paradigma das concepções e dos procedimentos de gestão. Com relação à gestão de pessoas, averiguamos que as escolas investigadas passam por situações que envolvem a necessidade de engajamento dos servidores e o enfrentamento de regras impostas por níveis hierárquicos que estão acima da governabilidade do Diretor Escolar, principalmente, quanto à lotação de

Mestre em Educação pela Universidade Federal de Rondônia; Licenciatura em Pedagogia pela Universidade Federal de Rondônia.

2 Doutor e Mestre em Educação pela Universidade Federal de Pelotas. 
profissionais nas escolas onde atuam, o que, de certa forma, preocupa esses gestores, na perspectiva do alcance dos resultados gerenciais esperados - requisitos necessários ao pleno cumprimento da finalidade educacional.

Palavras-chave: Gestão Escolar. Educação Integral. Diretor Escolar. Gestão de pessoas.

Abstract: This study is a result of a descriptive research developed on a qualitative approach, part of a Master's Thesis. The investigation aimed to analyze, on the School Director conception of how he has dealt with people management in the school scope to achieve goals and objectives in a full-time education context. We asked ourselves: what challenges related to people management are faced by the School Director? The data were collected through interviews, with the research participants being two Directors who work in schools that offer full-time high school in two municipalities in the state of Rondônia, Western Brazilian Amazon. The data were submitted to content analysis and part of its results are presented in this article through the category defined a priori called "Challenges of people management in the context of Full-Time High Schools". The research found the use of a standard management model based on the commitment to the integrality of educational action and that both schools are undergoing processes of paradigm of management concepts and procedures changes. With regard to people management, we discovered that the investigated schools go through situations that involve the need for engagement of civil servants and facing rules imposed by hierarchical levels that are above the School Director's governability, especially regarding the number of professionals in schools where they work, which, in a way, worries these managers, from the perspective of expected managerial results achieving - requirements necessary for the full fulfillment of the educational purpose. Keywords: School Management. Full-time education. School Director. People management.

Resumen: Este estudio es resultado de una investigación descriptiva, con enfoque cualitativo, que forma parte de una Tesis de Maestría. La investigación tuvo como objetivo analizar, en la concepción del Director de la Escuela, cómo ha abordado la gestión de personas en el contexto escolar para lograr metas y objetivos en el contexto de la educación integral. Nos preguntamos: ¿a qué retos relacionados con la gestión de personas se enfrenta el Director de la Escuela? Los datos fueron recolectados a través de entrevistas, siendo los sujetos participantes dos directores que trabajan en escuelas que ofrecen educación secundaria de tiempo completo en dos municipios del estado de Rondônia, en la Amazonía occidental brasileña. Los datos fueron sometidos a análisis de contenido y, en este artículo, se presentan los resultados de la categoría de análisis definida a priori "Retos de la gestión de personas en el contexto de las Escuelas Secundarias de Tiempo Completo". La investigación encontró el uso de un modelo de gestión estándar basado en el compromiso con la integralidad de la acción educativa y que ambas escuelas están atravesando procesos de cambio en el paradigma de conceptos y procedimientos de gestión. En cuanto a la gestión de personas, encontramos que las escuelas investigadas atraviesan situaciones que involucran la necesidad de la contratación de los funcionarios y enfrentan reglas impuestas por niveles jerárquicos que están por encima de la gobernabilidad del Director de la Escuela, especialmente en cuanto al número de profesionales en las 
escuelas donde trabajan, lo que, en cierto modo, concierne a estos gerentes, en la perspectiva de lograr los resultados gerenciales esperados - requisitos necesarios para el pleno cumplimiento de la finalidad educativa.

Palabras clave: Gestión escolar. Educación Integral. Director de escuela. Gestión de personas.

Recebido em 22 de novembro de 2020 Aceito em 16 de fevereiro de 2021

\section{INTRODUÇÃO}

A escola, espaço de múltiplas vivências, é foco de reflexões por parte dos estudiosos que propõem explicações relativas aos processos que se desenvolvem no seu interior. A gestão escolar, parte desse espaço, vem sendo considerada o eixo organizacional e operacional dos processos educacionais que constituem as escolas.

Libâneo (2015) explica que os estudos referentes à escola como organização de trabalho não são novos, existindo pesquisas sobre a administração escolar que remontam aos pioneiros da educação nova, na década de 1930. Esses estudos, segundo o autor, ocorreram no âmbito da administração escolar e estiveram marcados por uma concepção escolar burocrática e funcionalista, aproximando as características da organização escolar às da organização empresarial. Nas visões de Sander (2005) e Libâneo (2015), a história da administração escolar indica que as políticas educacionais no Brasil, sobretudo, a partir da década de 1990, têm enfatizado o fenômeno da gestão escolar no campo teórico/prático como veículo de materialização de objetivos e metas politicamente concebidos e de forte vinculação da gestão escolar à gestão empresarial.

Gomes (2009) explica que houve épocas em que o diretor escolar desenvolvia tarefas elementares e restritas ao zelo pelo bom funcionamento da escola. No entanto, o momento atual exige da escola o cumprimento de sua função social e o alcance de seus objetivos e metas gerenciais. Nesse contexto, não somente o professor precisa inovar sua prática pedagógica, mas todos os que fazem parte da gestão educacional devem assumir atitudes condizentes com a realidade histórica que lhes é imposta e as responsabilidades desse novo século. É salutar, nessa perspectiva, portanto, provocar mudanças políticogerenciais no intuito de, cada vez mais, aprimorar métodos de gestão e procedimentos de trabalho no campo educacional.

Para Sander (2005), a forma de trabalho no âmbito interno das instituições educacionais está vinculada às modificações não apenas ao fazer pedagógico, mas, 
concomitantemente, àquelas desenvolvidas no cotidiano da escola - que também passam pelos processos administrativos que constituem essas instituições. 0 desenvolvimento de tecnologias de gestão vem favorecendo a promoção de políticas e práticas educacionais, possibilitando seu uso orientado e ajustado às necessidades das instituições escolares. Há recursos de gestão que, inclusive, podem ser aliados na condução do processo pedagógico, o que possibilita a conquista de resultados não apenas em termos administrativos, como no desenvolvimento de práticas pedagógicas de boa qualidade que também são resultantes de uma gestão escolar responsável e competente administrativamente - focada não somente em tarefas, mas em pessoas. Na visão de Libâneo (2015, p. 10), "o modo como a escola funciona, suas práticas de organização e gestão, fazem diferença em relação aos resultados escolares." Com referência a essas práticas na gestão escolar, e com base na concepção desse autor, destacamos: a capacidade de liderança dos dirigentes, sobretudo, do diretor; a gestão participativa; o clima de trabalho; a organização do ambiente escolar e; as relações entre os sujeitos escolares.

A educação de tempo integral, por seu turno, é um dos desafios à gestão educacional do século XXI. No sentido aqui empregado, é uma modalidade de educação integral que nasce, oficialmente, com a política federal estabelecida pela Portaria Interministerial $n$. 17/2007, que cria o Programa Mais Educação (BRASIL, 2007), mas, de acordo com Maciel, Silva e Frutuoso (2019), as experiências pedagógicas brasileiras com educação integral possibilitam sintetizá-las em três modalidades: a educação integral liberal, a que correspondem a EscolaParque de Salvador e Brasília-DF; o tempo integral, onde se incluem, além das experiências advindas dos marcos legais de 2007, 2010 e 2014, os Centros Integrados de Educação Pública (CIEP) e os Centros Educacionais Unificados (CEU) e; finalmente, a educação integral politécnica, na qual se inclui o Projeto Burareiro de Educação Integral e outras experiências de natureza emancipatória.

Adotando a legislação vigente acerca da Educação Integral, e levando em consideração a realidade do estado de Rondônia, acpesquisa a qual este recorte se refere partiu da seguinte questão problematizadora: quais desafios relacionados à gestão de pessoas são enfrentados pelo Diretor Escolar no âmbito da administração de uma escola de tempo integral? Em consonância com esse questionamento, traçamos como objetivo geral analisar, na concepção do Diretor Escolar, de que forma tem lidado com a gestão de pessoas no âmbito escolar para o alcance de metas e objetivos no contexto da Educação Integral.

Adotamos como referenciais teóricos principais ao longo do texto os estudos de Chiavenato (2005), Gomes (2000), Libâneo (2015), Lück et al. (2012) e Sander (2005, 2007) sobre administração e gestão escolar, além de legislações pertinentes e as pesquisas de Maciel e colaboradores sobre a Educação Integral no estado de Rondônia - Maciel e Braga (2007); Maciel, Jacomeli e Brasileiro (2017); Maciel, Silva e Frutuoso (2019); e Frutuoso (2004). Para 
alcançar o objetivo proposto, foi realizada uma pesquisa ${ }^{3}$ do tipo descritiva, de abordagem qualitativa (BOGDAN; BIKLEN, 1994; GIL, 2017), tendo sido utilizada a entrevista semiestruturada como instrumento de coleta de dados (GIL, 2017), levada a cabo com dois Diretores de escolas de Tempo Integral de duas cidades diferentes do estado de Rondônia. A Análise de Conteúdo como abordagem para a análise dos dados (BARDIN, 2011).

0 presente artigo foi estruturado iniciando com esta introdução, oferecendo ao leitor uma ideia da temática a ser dissertada. A seguir, aborda concepções e problematiza a função social da escola e da gestão escolar, com foco em especificidades da Educação Integral. Na sequência, tratamos das principais concepções e perspectivas da Educação Integral e do Programa Escola do Novo Tempo no Estado de Rondônia. Em seguida, caracterizamos o estudo empírico e os aspectos metodológicos da pesquisa. Dando continuidade, analisamos os dados coletados com a finalidade de descrevê-los e interpretá-los, tendo sido selecionada a categoria de análise denominada "Desafios da gestão de pessoas no contexto das Escolas de Ensino Médio em Tempo Integral" para este recorte. Finalmente, apresentamos nossas considerações finais.

\section{A FUNÇÃO SOCIAL DA ESCOLA E O PAPEL DA GESTÃO ESCOLAR}

A escola não está isolada da sociedade, ela está no seu interior: a escola é uma organização social. Segundo Alonso (1988), essa tendência de classificar a escola como uma organização construída socialmente e com identidade própria se alicerça nas concepções administrativas contemporâneas - de acordo com suas características enquanto organização histórica e culturalmente constituída.

Lück et al. (2012) conceituam a escola como uma organização social, parte de uma coletividade dinâmica e intencionalmente organizada com o objetivo de promover o desenvolvimento de cidadãos críticos mediante suas compreensões de si mesmos e de seus papéis nessa mesma sociedade pela vivência de experiências sociais significativas:

\footnotetext{
[A escola] é uma organização social, isto é, uma coletividade dinâmica, intencionalmente organizada com o objetivo de promover com seus alunos o desenvolvimento de cidadãos críticos, mediante sua compreensão do mundo,
}

Os dados foram coletados no primeiro semestre de 2018, de acordo com agendamento prévio junto aos Diretores das escolas pesquisadas. 
de si mesmos e de seu papel nesse mundo, pela vivência de experiências sociais significativas. (LÜCK et al., 2012, p. 85).

Esses autores recohecem a escola, portanto, como uma organização a serviço da coletividade com a incumbência de educar seus cidadãos de modo que possam participar efetivamente da sociedade. Para tal, necessita de uma estrutura organizativa que the permita cumprir com seus objetivos. Certamente, a Educação tem de enfrentar o desafio das mudanças contemporâneas se quiser se manter atualizada em suas atribuições enquanto organização social. Para tanto, deverá rever o significado social da gestão escolar e suas contradições, equacionando as novas demandas e avaliando a sua eficácia para proporcionar um ensino de melhor qualidade a seus estudantes. Vieira, Almeida e Alonso (2003) salientam que essas mudanças devem considerar diferentes demandas e expectativas colocadas pela educação: atender às demandas econômicas e sociais decorrentes da expansão do mercado e possibilitar a reconstrução de culturas nacionais e locais, tendo como foco a efetiva aprendizagem de seus estudantes.

Mudanças sociais, políticas e econômicas, ao longo das últimas décadas, vêm exigindo da escola mudanças também em sua gestão. Mudanças desde a sua estrutura básica, passando por metas e objetivos gerenciais, culminando nos processos de ensino e de aprendizagem dentro das salas de aula. Segundo Gomes (2009), a escola necessita de mudanças em sua estrutura e em sua organização com vistas a propiciar maior flexibilidade para o desenvolvimento de novos projetos educacionais. Para que essa mudança ocorra, é necessário desencadear processos baseados em políticas públicas sintonizadas com as novas exigências sociais. No entanto, o fato é que gestores são pressionados a gerar resultados, gerenciar e otimizar recursos financeiros, envolvidos todo o tempo em atividades administrativas e pedagógicas. 0 que observamos em nossas escolas, para dificultar ainda mais esse quadro, são diretores, muitas vezes, fazendo verdadeiros malabarismos para manter a estrutura básica da instituição em funcionamento.

Observamos a compatibilidade de ideias entre Lima (2000) e Gomes (2009) quando esses autores destacam o fato de que existe considerável pressão sobre os gestores visando a melhora dos resultados da escola: financeiro-administrativos e relativos ao desempenho dos estudantes. Contudo, para a gestão dar conta dessas demandas com efetividade, necessita passar por mudanças significativas, o que demanda formação de educadores-gestores preparados para lidarem com uma escola concebida como organização social: capacitados a partir de concepções pedagógicas e conhecimento sobre administração, sem perder de vista a função social da escola e a realidade da comunidade que a constitui histórica e culturalmente. 
A partir das teorias gerais de administração propostas por Chiavenato (2005), apresentamos os elementos fundamentais de uma organização, acentuando que a marca do funcionamento de cada organização decorre de como se inter-relacionam os seguintes elementos:

Quadro 1 - Principais elementos que caracterizam uma organização

\begin{tabular}{|l|l|}
\hline EEEMENTOS & \multicolumn{1}{c|}{ DESCRIÇÃO } \\
\hline Objetivos & $\begin{array}{l}\text { Os propósitos que orientam a atividade e que devem ser revisados e reformulados de forma } \\
\text { permanente. }\end{array}$ \\
\hline Recursos & $\begin{array}{l}\text { Elementos humanos, materiais e funcionais (tempo, formação) usados pela organização para } \\
\text { levar adiante um projeto. Inclui também os métodos e instrumentos aplicados para o funcio- } \\
\text { namento institucional. }\end{array}$ \\
\hline Estrutura & $\begin{array}{l}\text { Os órgãos do governo, o sistema de regulamentaçães que o articula e o conjunto de equipes, } \\
\text { cargos e serviços. }\end{array}$ \\
\hline Cultura & $\begin{array}{l}\text { 0 conjunto de princípios, significados, valores e crenças compartilhados pelos membros da } \\
\text { organização e que dão sentido as suas condutas. }\end{array}$ \\
\hline Entorno & $\begin{array}{l}\text { Os elementos externos que influenciam na organização, tais como sua localização geográfica, } \\
\text { o nível socioeconômico e cultural da população, características da comunidade. }\end{array}$ \\
\hline
\end{tabular}

Fonte: adaptado de Chiavenatto (2005).

Gomes (2009) reitera que as organizações educativas são sistemas complexos e dinâmicos que devem executar, concomitantemente, as funções de educar e administrar. Contudo, percebe-se, ao pesquisar sobre as estruturas organizacionais de escolas públicas com as quais nos relacionamos, o desconhecimento de conceitos básicos de administração, mesmo aqueles mais elementares - como os acima apresentados no Quadro 1. Noções de gestão, como as pedagógicas, são pré-requisitos basilares para qualquer diretor de escola. Lück et al. (2012) expressam preocupação sobre a formação de nossos educadores para a gestão escolar:

\footnotetext{
Muito mais do que em quaisquer outras épocas, quando os sistemas e unidades educacionais nem sequer admitiam utilizar os mecanismos e instrumentos gerenciais disponiveis nos setores produtivos, há necessidade, hoje, de considerarmos que o desenvolvimento de conhecimentos e a formação de profissionais entendidos em gestão educacional, capazes de implementar e operar as transformações necessárias dos sistemas de ensino e escolas, é prioritário, por ser condição fundamental para o imprescindivel salto qualitativo da educação brasileira. (LÜCK et al., 2012, p. 23-24).
} 
Lima (2000) explica que, cada vez mais, têm se tornado comuns nas escolas mecanismos de eficiência, padrões de desempenho e a introdução de indicadores de referências para a melhoria contínua da educação, como, por exemplo, indicadores administrativofinanceiros ou que apontam o rendimento escolar dos estudantes. Cabe aqui questionar se os diretores de escolas, gestores máximos dessas organizações, estão preparados para trabalhar com esses indicadores e se os cursos de formação inicial estão sintonizados com esse tipo de exigência que se faz aos gestores das escolas do século XXI.

Para Sander (2007), o diretor é um gestor educacional e um administrador geral, responsável pela manutenção do regimento interno da escola e por viabilizar as melhores condições possíveis para que os processos de ensino e de aprendizagem transcorram como o que está preconizado no seu projeto pedagógico. De acordo com Sander (2005), os educadores que atuam na gestão de uma escola precisam compreender os três níveis da gestão educacional.

No primeiro nível, a gestão da Educação é compreendida como prática pedagógica, estando a aprendizagem no centro da prática educativa. 0 gestor, nesse nível, não estará preocupado somente com as exigências burocráticas, pois deverá se constituir em "um líder intelectual responsável pela coordenação do projeto pedagógico da escola." (SANDER, 2005, p. 64). Sendo assim, a função principal do diretor é facilitar os processos de desenvolvimento humano, colocando em prática a proposta pedagógica da escola e tendo como função central propiciar e acompanhar as atividades ligadas diretamente ao ensino, que envolve desde o planejamento pedagógico até as atividades-fim concretizadas nas salas de aula da instituição.

No segundo nível, Sander (2005) explica que a função da administração é atender às necessidades estruturais e burocráticas da escola. Esse nível da administração escolar pode desvelar parte de seu funcionamento em conjunto com os outros dois níveis: o pedagógico e o político. Nesse aspecto da gestão, Sander (2005, p. 65) enfatiza que, "muitas vezes, a rigidez da burocracia escolar inibe a participação dos pais e membros da comunidade na definição dos destinos da escola e na sua organização e gestão." Nesse contexto, a gestão da escola, na pessoa do diretor e por meio do Conselho Escolar, têm o papel de desenvolver um clima organizacional propício à participação democrática entre equipe gestora, docentes, discentes e membros da comunidade - evidenciando a função política do cargo que ocupa.

No último e terceiro nível definido por Sander (2005), justamente, o autor compreende a administração da educação escolar como prática política, que diz respeito à interface da escola com seu entorno, considerando os eixos político, cultural e econômico. Nesse nível da gestão, o diretor trabalha com atenção prioritária em sua capacidade de resposta às necessidades e aspirações da comunidade escolar, em uma espécie de diálogoponte entre os profissionais da organização escolar, a secretaria ao qual a instituição escolar está vinculada e os membros da comunidade que a constitui. A dimensão política diz respeito, 
também, às formas de condução dos processos internos decisórios, o que corresponde às formas utilizadas pelos gestores com vistas às tomadas de decisão e aos encaminhamentos dos assuntos inerentes ao contexto escolar.

A administração é uma atividade de apoio aos processos internos da escola, sejam eles pedagógicos, administrativos ou políticos, devendo todos serem valorizados como meios para a melhora dos serviços educacionais ofertados em sua atividade-fim. Para Lück et al. (2012), os processos de gestão escolar pressupõem ação ampla e contínua que envolve múltiplas dimensões, tanto pedagógicas quanto técnicas e políticas que só se efetivam, de fato, quando articuladas e em prol da execução das atividades pedagógicas. Os diretores, nessa perspectiva gerencial, tornam-se líderes capazes de identificar as necessidades da instituição, gerar compromissos coletivos, fomentar a participação da comunidade e formar cidadãos críticos.

Considerando, em especial, a relevância do papel do Diretor Escolar, discorreremos, na sequência, sobre a implantação do Programa Escola do Novo Tempo no estado de Rondônia e seus desafios à gestão escolar dentro do escopo da Educação Integral.

\section{O PROGRAMA ESCOLA DO NOUO TEMPO: A IMPLANTAÇÃO DO ENSINO MÉDIO EM TEMPO INTEGRAL (EEMTI) NO ESTADO DE RONDÔNIA}

A retrospectiva histórica do Ensino Médio aponta diversos caminhos percorridos por meio da implantação de políticas asseguradas por legislações, com a finalidade de mudar o rumo do Ensino Médio brasileiro. A Resolução CNE/CP n 4, de 17 de dezembro de 2018, institui a Base Nacional Comum Curricular na Etapa do Ensino Médio (BNCC-EM) (BRASIL, 2018) como etapa final da Educação Básica.

A experiência do estado de Rondônia com a educação integral tem origem com o Projeto Burareiro de Educação Integral, em janeiro de 2005, na gestão do então prefeito Confúcio Moura, do Município de Ariquemes (MAClEL; BRAGA, 2007). Esse Projeto foi susbstituído, a partir de setembro de 2006, pelo Projeto Burareiro - Escola de Tempo Integral, instituído pela Lei Municipal 1.217, de 21 de junho de 2006 (ARIQUEMES, 2006).

A manutenção do nome Burareiro, mas com a mudança de Educação Integral para Escola de Tempo Integral, é profundamente significativa, porque enseja a mudança não somente de orientação epistemológico-pedagógica, mas, também, a modalidade - o 
tipo - de educação integral que, a partir dali, a educação tomaria. ${ }^{4}$ Priorizar-se-ia o tempo em detrimento da educação, o que não era nenhuma novidade, haja vista o que houvera acontecido com outras experiências pedagógicas brasileiras, entre elas os CIEP, do Rio de Janeiro, antecipando-se, assim, ao que viria, pelo Governo Federal, em 2007.

Com efeito, a modalidade de tempo integral, criada pela Portaria Interministerial $n$. 17/2007, tem por objetivo, segundo Maciel, Jacomeli e Brasileiro (2017), suplementar os sistemas municipais e estaduais de educação por meio de assistência técnica e financeira, para que possam ampliar a jornada escolar mediante o oferecimento de atividades nos mais diferentes campos de conhecimentos e práticas socioculturais. Concebida assim, a modalidade de tempo integral se constitui de três núcleos conceituais determinantes: a ampliação da jornada escolar, das áreas de conhecimento e das atividades socioculturais. Desses três núcleos, predominará a noção de ampliação da jornada escolar, o tempo integral, cuja concepção definitivamente será consolidada pelo Decreto n. 7.083/2010 (BRASIL, 2010) e ratificada pela Lei n. 13.005/2014 (BRASL, 2014).

Em 2011, Confúcio Moura, depois Governador do estado de Rondônia, criou as Escolas de Educação Integral do Estado de Rondônia, por intermédio da Lei 2.416, de 18 de fevereiro de 2011, com base na qual o Conselho Estadual de Educação, em 5 de novembro de 2012, aprovara o Projeto Guaporé de Educação Integral. De acordo com Carvalho (2018, p. 91), um projeto "inspirado" na experiência de Ariquemes e que, de fato, apenas subistituiuse o termo Burareiro por Guaporé. ${ }^{5}$ Novamente, o Projeto traz, ao menos no título, o termo Educação e não tempo, dando a entender que, seis anos depois, o mesmo dirigente político retomaria a modalidade de educação integral. Ledo engano.

Quatro anos depois - após o Ministério da Educação instituir, por meio da Portaria n. 1.145, de 10 de outubro de 2016, o Programa de Fomento à Implantação de Escolas em Tempo Integral para a melhoria do Ensino Médio, com fundamento na Medida Provisória n. 746, de 29 de setembro de 2016 (BRASIL, 2016), que já ouvera, um mês antes, portanto, instituído a Política de Fomento à Implementação de Escolas de Ensino Médio em Tempo Integral - o Governo do Estado institui a Lei Complementar n. 940, de 10 de abril de 2017 (RONDÔNIA, 2017), enquanto a Secretaria de Educação se apressava a enviar, ao Conselho Estadual de Educação, o Projeto Pedagógico do Programa Escola do Novo Tempo, aprovado pela Resolução 1.228, em 12 de março de 2018 (RONDÔNIA, 2018).

Essa breve análise histórica dos Projetos, Programas e Leis do estado de Rondônia confirma que o estado teve duas chances, pelo mesmo dirigente político, de executar uma

4 Detalhes do processo de implantação do Projeto Burareiro de Educação, incluindo as razões que levaram à sua substituição, bem como as implicações epistemológicas decorrentes da mudança de conceito e consequente fundamentação teórica, encontram-se em Frutuoso (2014).

5 Em Carvalho (2018), pode-se verificar uma breve, porém, precisa descrição das origens da Educação Integral em Rondônia. 
política de Educação Integral (Burareiro de 2005 e Guaporé), mas optou por duas políticas de Tempo Integral (Burareiro de 2006 e Escola do Novo Tempo). ${ }^{6}$

0 Projeto Escola do Novo Tempo começou a ser implantado em março de 2017, inicialmente, em dez escolas da rede estadual de ensino, nos seguintes municípios: Porto Velho, Jaru, Ji-Paraná, Cacoal, Pimenta Bueno, Guajará Mirim, Ariquemes, Rolim de Moura, Alta Floresta e Espigão do Oeste. No ano de 2018, foi inserida mais uma escola ao projeto, localizada no município de Vilhena, totalizando onze escolas. As Escolas de Ensino Médio em Tempo Integral - Novo Tempo, até o ano de 2019, receberam 3.500 (RONDÔNIA, 2019) ${ }^{7}$ estudantes matriculados entre as onze escolas. 0 Projeto tem como meta atender 4.160 alunos do Ensino Médio e cumprir as metas 3 e 6 do Plano Estadual de Educação de Rondônia, com vigência até 2024.

- Meta 3: ampliar atendimento escolar para a população de 15 a 17 anos e elevar, até o final de 2024, a taxa de matrículas do Ensino Médio de 45,7\% para $85 \%$ nessa faixa etária (p. 90);

- Meta 6: oferecer educação em tempo integral em, no mínimo, $20 \%$ das escolas públicas de educação básica até o final de 2024. (RONDÔNIA, 2015, p. 98).

Essa implantação foi possível a partir da adesão ao Programa de Fomento à Implementação de Escolas em Tempo Integral, instituído pela Portaria/MEC n 1.145, de 10.10.2016, em observância à Medida Provisória $n^{\circ}$ 746, de 22 de setembro de 2016, convertida na Lei $n^{\circ}$ 13.415 de 16 de fevereiro de 2017, alterando a LDB de 1996 e instituindo a Política de Fomento à Implementação de Escolas de Ensino Médio em Tempo Integral em seu Art. 13 (BRASIL, 2017). 0 parágrafo único do artigo supracitado informa, em suma, que os recursos devem ser repassados pelo MEC pelo prazo de dez anos por escola, de acordo com o termo de compromisso.

Os recursos destinados à implementação e ao desenvolvimento do Programa de Fomento às EEMTI que atende o estado de Rondônia se originam na dotação orçamentária consignada no Orçamento da União por meio do Fundo Nacional de Desenvolvimento da Educação (FNDE), conforme disposto no Art. 9 da Medida Provisória $n^{\circ} 746$, de 22 de setembro de 2016. 0 FNDE é o responsável pelo repasse de recursos destinados a reformas e construções, merenda escolar, compra de materiais de laboratório, materiais de consumo, utensílios de cozinha e mobiliários das escolas contempladas com o referido Programa. ${ }^{8}$

Discussão atualizada sobre as modalidades de Educação Integral pode ser encontrada em Maciel e Silva (2019).

Em pesquisa ao portal da Secretaria de Educação do Estado de RO, os dados estatísticos não estão disponíveis.

No estado em Rondônia, o Programa Escola do Novo Tempo foi instituído pela Lei Complementar $n^{\circ} 940$, de 10 de abril de 2017. Além da adesão ao referido Programa, a SEDUC/RO estabeleceu parceria com o Instituto de Corresponsabilidade pela Educação (ICE). 
De acordo com a matriz curricular adotada pelo Programa Escola do Novo Tempo, constam os seguintes indicadores: 208 dias letivos anuais; módulo semanal com 40 semanas; 45 aulas semanais; nove aulas diárias; módulo-aula de 50 minutos; intervalo de 20 minutos por turno; intervalo para almoço de 1h20 min; carga horária anual de 1.500 horas, com 1.000 horas para as disciplinas da Base Nacional Comum e 500 horas para as da Parte Diversificada, sendo 133 horas para as disciplinas das áreas de Conhecimento e 367 horas para os Componentes Curriculares Integradores.

Quanto ao regime escolar, a matrícula do estudante é anual, a transferência segue as normas estabelecidas na legislação vigente, a frequência é verificada conforme disposto na legislação vigente, especialmente, nos artigos 16 e 17 da Portaria $n^{\circ}$ 4.563/2015-GABISEDUC. 0 sistema de avaliação e recuperação da aprendizagem atende o que estabelecem a Portaria $n^{\circ}$ 4.563/2015-GABISEDUC e a Portaria n ${ }^{\circ}$ 2.944/201-GABISEDUC, inclusive, quanto à progressão parcial. Na verificação do rendimento escolar, as notas devem ser expressas numa escala de zero a dez, devendo prevalecer os aspectos qualitativos sobre os quantitativos e os resultados obtidos no decorrer do ano letivo sobre os do exame final.

A implementação do Projeto está a cargo da SEDUC, por meio da Comissão de Coordenação do Programa Escola do Novo Tempo, da qual fazem parte a Diretoria Geral de Educação, a Gerência de Educação Básica, a Subgerência de Educação Integral e a Equipe de Implantação do Projeto e, ainda, por meio da Equipe Escolar, composta pelos gestores, técnicos, docentes e pessoal de apoio administrativo, devidamente habilitados e lotados na Escola de Ensino Médio em Tempo Integral.

Por meio do Programa Escola do Novo Tempo, a SEDUC deve ofertar aos educandos educação diferenciada, em regime escolar de tempo integral, desencadeando a formação de cidadãos capazes de interagir na sociedade em que vivem. Em termos práticos, essa proposta educativa indica a abertura da escola para as outras dimensões do ser humano. Formar o cidadão integral pressupõe a oferta de educação cujo maior foco é assegurar que os estudantes tenham condições de fazer uma "leitura crítica da vida"; que os levem, por si mesmos, a usar o conhecimento como instrumento de aprendizagem ao seu alcance de forma útil e significativa. Costa (2001) destaca que esse modelo educacional visa a oferta de uma Educação interdimensional, na qual o educador é mais do que um transmissor ou aplicador de conteúdos elaborados em outros contextos, sendo convocado e incentivado a produzir conhecimento através da sua própria prática, aprendendo e ensinando a pensar a vida e a viver o pensamento.

Nessa proposta de formação, o protagonismo juvenil é compreendido, aceito e praticado como laboratório de Educação e valores, sendo o estudante o ator principal de seu processo de desenvolvimento. As premissas do modelo pedagógico têm o foco no jovem e em seu projeto de vida, que é o seu eixo, sua centralidade e sua razão de existir. É nele 
que o currículo e a prática pedagógica realizam o seu sentido, no aspecto formativo e contributivo, na vida do jovem. Dessa forma, esses estudantes são levados a refletirem sobre seus sonhos, suas ambições e sobre aquilo que desejam para as suas vidas, onde almejam chegar e que pessoas desejam ser, que valores querem construir e instituir em sua vida como fundamentais.

Contudo, diante de todas as variantes complexas que constituem qualquer processo educacional inovador na educação, a gestão escolar necessita ser planejada e repensada na perspectiva de estabelecer formas estruturantes para desenvolver as ações a que se propõe, como no caso específico da implementação da Educação Integral. Nesse sentido, como garantir essa implementação com êxito? Qual o papel do Diretor Escolar nesse processo? Como se configura a gestão de pessoas no âmbito da Educação Integral? 0 ambiente escolar é rico nas indicações que nos apresenta cotidianamente, sendo possível, inclusive, observar como a coresponsabilidade direta de cada ator impacta a estruturação educativa.

A seguir, descreveremos um recorte do estudo empírico realizado junto a diretores de duas das onze Escolas de Ensino Médio em Tempo Integral - Novo Tempo de Rondônia.

\section{CARACTERIZAÇÃO DO ESTUDO EMPÍRICO}

Tratou-se de uma pesquisa descritiva, de abordagem qualitativa (BOGDAN; BIKLEN, 1984; GIL, 2017), realizada em duas escolas estaduais de ensino médio em tempo integral dos municípios de Porto Velho (capital do estado de Rondônia) e Espigão do Oeste, contempladas pelo Programa Escola do Novo Tempo.

Optamos por dois instrumentos para a coleta de dados: o questionário (GIL, 2017), utilizado para coletar dados que definiram o perfil dos sujeitos da pesquisa de modo a caracterizá-los com informações pessoais e profissionais atualizadas; e foi a entrevista semiestruturada (GIL, 2017), elaborada com base nos objetivos específicos propostos. Ambos foram aplicados a dois diretores escolares ${ }^{9}$ entre os meses de junho e julho de 2018.

Com intuito de analisar o material obtido por meio do questionário e da entrevista, tabulamos os dados das respostas ao questionário e transcrevemos. Na sequência, providenciamos a consolidação dos dados com o propósito de identificarmos as informações

\footnotetext{
9 Nem os sujeitos e nem as instituições que dirigiam à época da pesquisa tiveram seus nomes revelados, com o intuito de presevar suas indentidades e por critérios de confidencialidade. Foram utilizadas as seguintes idenfiticações: Escola 1 (E1), Gestor 1 (G1), Escola 2 (E2) e Gestor (G2).
} 
expressas nas falas. Para tanto, optamos por uma análise temática categorial, recorrendo à técnica de análise de conteúdo - que para Bardin (2011, p. 48) o termo designa:

\begin{abstract}
[u]m conjunto de técnicas de análise das comunicações visando a obter por procedimentos sistemáticos e objetivos de descrição de conteúdos das mensagens indicadores (quantitativos ou não) que permitam a inferência de conhecimentos relativos às condições de produção/recepção (variáveis inferidas) dessas mensagens.
\end{abstract}

A técnica categorial foi composta por procedimentos sistemáticos que proporcionaram o levantamento de indicadores qualitativos, permitindo a realização de inferências, em diálogo com referenciais teóricos, sobre os dados coletados. Por meio da análise de conteúdo categorial, as informações foram tratadas mediante três fases: préanálise, exploração do material e tratamento dos resultados e interpretações. No presente recorte, são apresentados e problematizados exclusivamente os dados da categoria de análise, definida a priori, denominada "Desafios da gestão de pessoas no contexto das Escolas de Ensino Médio em Tempo Integral".

Duas escolas, de duas cidades do estado de Rondônia, compuseram o lócus da investigação empreendida. Porto Velho e Espigão do Oeste. Porto Velho, capital do estado de Rondônia, que faz parte da Amazônia Ocidental brasileira, possui 34.096,338 Kma de área geográfica, com uma população de 529.544 pessoas, sendo o mais populoso do estado e o quarto da Região Norte do país. Além de concentrar o maior PIB (Produto Interno Bruto) do estado, é a capital brasileira com maior área territorial, com mais de 34 mil kma - mais extenso do que países como Bélgica e Israel. Espigão do Oeste está localizado na região leste de Rondônia, sendo o $13^{\circ}$ município mais populoso do estado, com uma população que ultrapassa os 33 mil habitantes. A cidade, que detém o $1^{\circ}$ maior PIB do estado, é conhecida por ser povoada por descendentes de pomeranos (IBGE, 2018).

As escolas E1 e E2 foram contempladas com o Programa Escola do Novo Tempo no ano de 2016, mas, somente em 2017, iniciaram as atividades no âmbito da Educação Integral. A Escola E1 (de Porto Velho) atua na sociedade há 42 anos e, a partir de 2017, seu atendimento se voltou apenas para estudantes do Ensino Médio em Tempo Integral, contando, quando da realização da pesquisa, com 417 estudantes distribuídos em doze turmas. A Escola E2 (de Espigão do Oeste) possui 45 anos de atuação e, na época da investigação, atendia, exclusivamente, estudantes na modalidade Ensino Médio em Tempo Integral, totalizando 313, distribuídos em dez turmas. Ambas as instituições foram selecionadas para a pesquisa contemplando dois critérios: ofertarem Ensino Médio em Tempo Integral e seus diretores aceitarem contribuir com o estudo. 
Ambos os gestores são graduados em cursos de licenciatura: G1 (mulher) em Letras/Português e G2 (homem) em Matemática. Os dois possuem especialização Lato sensu, a primeira em Educação Especial e o segundo em ensino de Matemática. Constatamos que nenhum deles tem formação para a atuação na gestão escolar e é importante destacar que, em licenciaturas que não em Pedagogia, os currículos dos cursos ofertam poucas disciplinas pedagógicas, em geral: Didática, Psicologia da Educação e Legislação Educacional. Como nem mesmo os cursos de especialização que fizeram foram direcionados à área da gestão educacional, tratam-se de profissionais praticamente sem formação para a atuação na gestão escolar, tampouco, para a Educação Integral. No tocante a suas experiências profissionais na Educação, variam entre 21 e 24 anos. Especificamente como gestores educacionais, G1 relatou ter nove anos de experiência e G2 dez. Na gestão da educação em tempo integral, ambos possuem dois anos de experiência.

A seguir, vamos buscar problematizar, a partir de dados coletados junto a esses dois diretores, suas percepções quanto aos desafios da gestão de pessoas no contexto das Escolas de Ensino Médio em Tempo Integral - em formato de síntese, apresentando os principais destaques, em virtude das limitações de espaço para o presente artigo.

\section{RESULTADOS E DISCUSSÕES}

Apresentaremos, nesta seção do texto, a análise dos resultados obtidos nas entrevistas junto aos Diretores Escolares, sujeitos participantes do referido estudo. Cabe, aqui, o registro inicial de que as principais barreiras e dificuldades apontadas pelos dois diretores são, prioritariamente, relacionadas às competências humanas e à incipiência nas políticas de gestão no que se refere à Educação Integral ao longo do percurso de implementação do Programa Escola do Novo Tempo.

A Diretora G1 revelou fatores associados especificamente aos servidores da escola, mais precisamente, ao engajamento das pessoas envolvidas na implementação do programa, enfatizando que essa variável tem causado desgaste durante o cotidiano de sua gestão:

Hoje, eu digo pra você que o estudante não me ocupa tempo. 0 que me ocupa o tempo hoje é o servidor. É eu saber que existe uma situação e que, de certa forma, é fácil de resolver, mas, ao mesmo tempo, é difícil porque eu dependo do outro. Dele entender que existe ele existe e tem uma função, ele tem um papel a cumprir, tem horário a cumprir e isso me desgasta [...] (G1) (informação verbal). 
G1 destaca o fato de que cada servidor tem uma função específica e um papel a cumprir na escola, e que cada um deve compreender que suas ações refletem nas atribuições de outros, como uma forma de interdependência dos processos internos para os trabalhos fluírem satisfatoriamente. Já em sua segunda fala, são destacadas suas iniciativas para incluir os servidores nas atividades da escola, fazendo uso de estratégias de socialização e diálogo:

\begin{abstract}
Eu creio que se torna mais dificil porque ele lo docente] também é formador de opinião e é aquela pessoa que, por ser formador de opinião, ele também contesta. [...] nós estamos num processo de formação de um modelo, nós estamos num processo que eu preciso que o outro compreenda que ele está no modelo de mudança. [...] ele vai passar por todo um processo de integração ao meio, de adaptação de ambiente, de permanência no ambiente por muitas horas, de convivência com as pessoas por muito tempo. Tenho uns dois professores que não estão ainda alinhados ao modelo. Aí já entraram mais três professores novos esse ano. Nós não podemos receber um professor, um funcionário sem que ele possa participar de uma formação, pelo menos uma miniformação, que ele possa compreender a estrutura da escola. (G1) (informação verbal).
\end{abstract}

Nos depoimentos de Gl, percebe-se a importância por ela atribuída ao comprometimento e ao engajamento dos servidores no contexto escolar, principalmente, no que se refere à adaptação ao novo modelo de gestão vivenciado pelas escolas pesquisadas. Mesmo algo básico, como a participação dos docentes em ações de formação continuada, dificulta o trabalho da diretora da escola e, consequentemente, a efetivação do Programa Escola do Novo Tempo.

0 depoimento de G1 nos leva a ponderar sobre dois aspectos. 0 primeiro, sobre a escola que pretende obter resultados na perspectiva de uma gestão eficaz e que deve considerar as pessoas como parte integrante de suas estratégias de planejamento e ações. Para além do conhecimento especializado, o diretor precisa compreender quais iniciativas serão necessárias para desenvolver e promover a motivação e o sentimento de pertencimento de cada servidor para o trabalho desenvolvido no interior da escola. 0 segundo aspecto está associado ao reconhecimento e à administração dessas expectativas pelo próprio gestor e também por cada membro da sua equipe gestora e docentes. A esse respeito, Chiavenato (2005) assinala que a perspectiva de desenvolvimento dos profissionais quanto à formação integral para o mundo do trabalho sinaliza a necessidade de iniciativas formativas em que as pessoas também possam se desenvolver plenamente, seja no campo técnico ou no comportamental. Para esse pesquisador,

a orientação das pessoas é o primeiro passo para a sua adequada aplicação dentro das diversas atividades dentro da organização. Trata-se 
de posicionar as pessoas em suas atividades na organização e esclarecer o seu papel e objetivos. Contudo, possuir recursos é necessário, mas não suficiente [...] (CHIAVENATO, 2005, p. 138).

Nesse contexto, verifica-se a importância da formação dos servidores, não apenas como uma iniciativa isolada e pontual, mas pela necessidade de as pessoas compreenderem e poderem se posicionar em relação ao seu papel e aos objetivos a serem alcançados, tanto na instância operacional ou tática de sua atuação, como em uma esfera mais estratégica da gestão educacional. Nesse sentido, o apontamento de G1, ao revelar que o servidor participe, ao menos, de uma "miniformação" para que possa compreender a estrutura da escola, demonstra conhecimento da necessidade de formar os funcionários da escola para que atuem de forma adequada em suas atribuições específicas e para o coletivo organizacional. Nessa direção, Ribeiro (1986) já qualificava os processos que ocorrem durante a administração escolar como sendo mais políticos e menos técnicos, a fim de garantir que as relações cotidianas na escola se pautem pela colaboração, o que, teoricamente, tende a potencializar e a aprimorar tanto as atividades individuais como as coletivas. Parece ser esse o caso de G1 que, como já sublinhamos, não teve formação específica para a gestão escolar, mas, que, no cotidiano, percebe nuances e os administra da forma que considera ideal para a execução de ações e projetos da escola.

Ainda em relação aos resultados a serem alcançados pela escola, destacamos, abaixo, a percepção do Diretor G2 quanto à relevância de trabalhar com servidores lotados nos quadros funcionais da escola que possam corresponder às suas necessidades de operabilidade:

\footnotetext{
[...] ○ que a gente precisa são os ambientes de aprendizagem como o coordenador do laboratório de informática, coordenador do laboratório seco e molhado, biblioteca que precisam ser profissionais altamente conhecedores do modelo de gestão, mas geralmente são lotadas pessoas que não tem muita força de vontade ou laudados que não se engajam muito no projeto. Então, recursos humanos não posso dizer que é $100 \%$ não, mas a parte de professor nós estamos satisfeitos. (G2) (informação verbal).
}

A partir dessa revelação, o sujeito aproveita a oportunidade para destacar um ponto positivo: a satisfação com os professores lotados na escola. Por outro lado, destaca os ambientes para os quais são necessários profissionais conhecedores do modelo de gestão em vigência. G2 denuncia que "tem recebido" profissionais "laudados" - aqueles que se encontram em processo de readaptação funcional ou com restrições ocupacionais e são encaminhados para as escolas, geralmente, lotados nos espaços por ele mencionados. G2 revela duas situações diferentes em relação à gestão de pessoas: a primeira está associada 
aos servidores readaptados em setores pedagógicos, ocupando vagas de liderança intermediária, na coordenação de ambientes de aprendizagem e; a segunda situação, relacionada a pessoas lotadas na escola "que não tem muita força de vontade" frente às ações e projetos do educandário.

A primeira situação nos chamou atenção e nos motivou a conhecer os critérios de lotação das pessoas em processo de readaptação funcional nas escolas públicas de Rondônia. Para a nossa surpresa, encontramos o dispositivo apresentado pela Lei Complementar $n^{\circ} 940$, promulgada em 10 de Abril de 2017, que institui o Programa Escola do Novo Tempo no Estado de Rondônia que, em seu artigo 8, define a composição das equipes, sendas destacadas, no referido documento (p. 04), as seguintes orientações:

\footnotetext{
[...] || - responsável pela biblioteca: profissional do magistério readaptado, responsável pela organização do espaço, com o objetivo de acompanhar as atividades desenvolvidas [...]; IV - responsável pelo laboratório de informática: profissional do magistério contratado especificamente para laboratórios de mídias integradas, e caso o município não possua essa contratação, que seja lotado um profissional do magitsério readaptado [...]; V - responsável pelo laboratório de secos e molhados: profissional do magistério readaptado, responsável pela organização do espaço [...]
}

Verificamos, então, que existe uma diretriz na própria lei que orienta a formação das equipes, que indica, preferencialmente, a lotação de profissionais readaptados na biblioteca, no laboratório de informática e no laboratório de secos e molhados. A situação deflagrada por G2 revela um desafio ao Diretor por ter que trabalhar com profissionais readaptados que, possivelmente, não possuem o conhecimento e as habilidades necessários àquela ocupação profissional e que, muito provavelmente, não apresentam o volume de trabalho desejável em virtude de suas limitações de saúde. Todavia, indicar servidores em setores pedagógicos estratégicos, como é a biblioteca, parece-nos uma decisão que deveria estar embasada em uma política sintonizada com ações que visem, primeiramente, a aprendizagem dos estudantes.

0 caso relatado por G2, e que vem se tornando comum em outras escolas do estado de Rondônia, demanda competência e habilidades do Diretor escolar para que esses profissionais readaptados produzam o que a função que ocupam demanda em termos do que se preconiza para esses espaços no cotidiano escolar e para a execução de projetos da instituição.

Para que os resultados dos projetos de uma escola sejam alcançados com êxito, seja ela ou não de tempo integral, a formulação das políticas de gestão de pessoas contribui para tomadas de decisões que impactam diretamente nas atividades da escola, pedagógica, administrativa ou politicamente (SANDER, 2005). Logo, a situação trazida sobre a política de readaptação nos parece um tanto desvinculada da negociação interna e distanciada da 
autonomia do Diretor. Essa situação revela contradições em relação ao novo modelo de gestão: há responsabilização dos diretores pelos resultados da escola, no entanto, com autonomia limitada de trabalho, mantendo, ou mesmo acentuando, o controle sobre os processos internos da escola pelas secretarias.

Em relação aos meios que servem à administração escolar, Ribeiro (1986) destaca-os em três grupos: humanos, legais e materiais. Para ele, em qualquer organização, os profissionais devem ser devidamente formados para as funções que ocupam e constantemente valorizados. Além disso, as diversas funções em uma organização não são individuais e sim tarefas coletivas, principalmente, em se tratando da unidade dos trabalhos coletivos desenvolvidos nas escolas.

Em vista da segunda situação, um profissional com "pouca força de vontade", provavelmente, causará impacto no desempenho nas atividades laborais demandadas pelo cotidiano escolar, ainda mais sendo ocupante de uma função de liderança intermediária, a qual requer competências comportamentais específicas para lidar com estudantes e servidores, além dos desafios decorrentes do conjunto de metas da escola e da implementação do EEMTI.

Mediante desafios e limitações impostas aos diretores escolares, as escolas El e E2, conforme seu plano de ação, até 2024, precisam contribuir com resultados para tornar o estado de Rondônia uma referência na Região Norte em termos de formação de estudantes por meio do ensino integral, proporcionando-lhes formação de boa qualidade e competências para enfrentarem a sociedade do século XXI em suas múltiplas contradições. Sander (2005; 2007) compreende que a competência humana do administrador da Educação se revela justamente na capacidade para conceber soluções e, por meio de sua liderança, implantá-las.

De acordo com Chiavenato (2005), para que uma organização possa existir, ela deve atender aos seguintes pré-requisitos: ter pessoas aptas a se comunicarem; a atuarem de forma conjunta e; a atingirem um objetivo comum. Contudo, em nosso entendimento, para que as escolas de tempo integral atinjam seus objetivos, é necessário que os gestores tenham plena participação e abertura para, então, satisfazer as demandas internas concernentes a problemas de qualquer natureza. Para Lück et al. (2012, p. 37), nessa linha de pensamento, quanto à gestão escolar, a

[...] liderança é, pois, um conceito complexo que abrange um conjunto de comportamentos, atitudes e ações voltadas para influenciar pessoas e produzir resultados, levando em consideração a dinâmica das organizações sociais [...] dilemas que necessitam ser mediados à luz de objetivos organizacionais elevados. 
Ainda no que tange aos recursos humanos nas escolas pesquisadas, evidenciamos os desafios de liderar pessoas nas palavras dos diretores escolares. Suas falas expressam certa preocupação com as relações interpessoais, principalmente, em relação à implementação do Ensino Médio em Tempo Integral nas instituições que dirigem. Abaixo, G1 nos revela que é necessário criar uma relação de confiança entre o líder e seus comandados:

\footnotetext{
[...] nós três precisamos comungar com as mesmas opiniões, tendo clareza dos objetivos que nós estamos hoje buscando, mas precisamos ter uma relação de confiança um no outro [...] e eu sei que esse é um papel desafiador pra mim. Meu maior desafio, hoje, é com pessoas. É eu conseguir, não com que as pessoas comunguem com as minhas ideias, [... meu maior desafio hoje é trazer resultados positivos. E que o outro compreenda isso também. (G1) (informação verbal).
}

Observamos a preocupação por parte da Diretora G1 em encontrar mecanismos para envolver "o outro" nas ações da escola, o que nos parece uma espécie de alinhamento de uma mesma direção em sua gestão. Ao lançar uso da expressão "nós três", G1 se refere a ela própria, mais o Coordenador Administrativo Financeiro (CAF) e o Coordenador Pedagógico (CP). Pelo o que compreendemos da prática das escolas pesquisadas, e de tantas outras em nossa atuação na Educação Básica, G1 adota a postura adequada no que se refere à gestão de pessoas, mostrando comprometimento com o projeto da escola que dirige. Com a definição clara de papéis e co-responsabilidades e sensação de pertencimento, G1 procura possibilitar a criação de um ambiente colaborativo e o menos conflituoso possivel na escola.

0 Diretor G2, por seu turno, sublinha a necessidade de trabalhar com profissionais atualizados, utilizando-se das expressões "mente nova" e "postura diferente". É possível perceber que ele se refere aos perfis de servidores lotados na escola, que sejam empenhados e focados nos resultados que a escola necessita entregar para a sociedade:

\footnotetext{
[...] um dos maiores desafios [...] é trabalhar com muitos profissionais que já estão ultrapassados ou que não querem mudança. [...] a gente precisa trabalhar com os técnicos, a gente precisa de gente, uma mente nova. [...] hoje nós precisamos nos despir de muitas práticas, de alguns valores [...] e essa mudança exige de nós postura diferente. E eu como gestora [...] tenho que me posicionar em relação a um servidor, as vezes adotar uma postura mais tradicional também. (G2) (informação verbal).
}

Corroborando com o que é desejado por G2, Chiavenato (2005, p. 406) assevera que 
a mudança é um aspecto essencial da criatividade e de inovação nas organizações de hoje. A mudança está em toda parte: nas organizações, nas pessoas, nos clientes, nos produtos e serviços, na tecnologia, no tempo e no clima. A mudança representa a principal característica dos tempos modernos.

Nessa linha de pensamento, compreendemos que não basta mudar o modelo de gestão se a ênfase na incorporação por novos comportamentos não está sintonizada com as pessoas. Defendemos que essa concepção deva ser considerada nas práticas inovadoras no âmbito escolar, sendo uma das bases para a descoberta e a adoção de novas atitudes e comportamentos. Não basta conhecer o modelo, é preciso que as pessoas conheçam sua essência, suas intencionalidades e suas contradições históricas (LIBÂNEO, 2015).

Nessa perspectiva, é importante destacar que faz parte do modelo de gestão de tecnologia educacional implantando em ambas as escolas pesquisadas um conjunto de premissas conceituadas como o ponto de partida para a definição de objetivos, prioridades e metas. No plano de ação, as premissas são marcos que representam os princípios básicos, aos quais se conectam objetivos, prioridades e resultados esperados. Entre elas, há pontos de partida para a formação continuada dos educadores, a fim de despertar nos mesmos a busca contínua pelo autodesenvolvimento permanente.

\section{CONSIDERAÇÕES FINAIS}

Durante a realização deste estudo, assumimos o desafio de investigar, na concepção de dois diretores, de que forma têm lidado com a gestão de pessoas no âmbito escolar para o alcance de metas e objetivos no contexto do Ensino Médio em Tempo Integral. Em ambas as escolas, verificamos o uso de um modelo padrão baseado na concepção e no compromisso com a integralidade da ação educativa, concebido como um conjunto de aç̃̃es que se apoiam entre si e se integram às propostas pedagógicas das instituições, estimulando que as partes envolvidas sintam-se motivadas a aprender e colocar em prática seus conhecimentos a serviço dos estudantes e de seu projeto de vida. Foi possivel averiguar que as escolas estão passando por processos de mudança no paradigma das concepções e práticas dos procedimentos de gestão, o que permite a compreensão de um aprendizado que se constitui ao longo das práticas em andamento.

Os achados, apresentados sinteticamente neste recorte, indicam a relevância do trabalho do gestor como condição para a determinação dos resultados que a escola deseja alcançar, seja por meio do aprimoramento dos processos educacionais como do engajamento 
da equipe de trabalho, visando a atividade-fim da escola de tempo integral: a formação integral dos estudantes.

Os resultados demonstram, ainda, que os diretores das duas escolas que implementaram o Ensino Médio de Tempo Integral compreendem a concepção da proposta de educação integral, mesmo sem formação inicial ou continuada direcionadas à gestão escolar ou à Educação Integral, mas que a mesma deve ser assumida por todos os agentes envolvidos no processo formativo dos jovens, sendo este um grande desafios, segundo suas percepções.

Ambos os diretores compreendem que os servidores, independente de sua área funcional, são fundamentais para que a formação integral dos educandos seja alcançada. Os diretores investigados sinalizaram em suas falas que uma gestão de pessoas desatrelada das necessidades da escola, provavelmente, não contribuirá para que os obstáculos cotidianos sejam ultrapassados ou que a implementação de projetos de maior complexidade sejam alcançada. Para tal, as competências funcionais e o engajamento dos servidores são fundamentais para o desenvolvimento organizacional como um todo, uma vez que o Diretor Escolar tem o desafio de gerir a escola juntamente às pessoas que a compõem.

No que se refere aos desafios relacionados à gestão de pessoas, ficaram evidentes as principais dificuldades relacionadas pelos diretores entrevistados: o engajamento por parte dos servidores e as regras impostas por níveis hierárquicos acima do Diretor Escolar quanto à lotação de profissionais em postos laborais específicos das escolas que gerenciam. Sendo assim, cabe destacar a necessidade de rever as políticas administrativas para que sejam lotados os profissionais com a formação e experiência adequados nos espaços que os demandam.

Pelo fato de as escolas pesquisadas estarem no quinto ano de implantação do Programa Escola Novo Tempo, é compreensivel que os envolvidos na sua implementação ainda estejam em processo de adaptação quanto às suas atribuições, incluindo seus diretores, requerendo, portanto, formação contínua de todos os servidores para a otimização do modelo de gestão implantado. Como proposta de agenda para projetos futuros, indicamos pesquisas com outras escolas do estado que estejam atuando mediante a implantação do programa e reconhecemos a limitação deste estudo no que se refere a um desejo de maior abrangência, para que fosse empreendido em escolas de outros municípios, o que a falta de financiamento não nos permitiu

Espera-se que essas reflexões possam oferecer indicativos sobre os desafios implicados na implantação de projetos educacionais de Educação Integral. Por fim, temos a convicção de que este estudo não se conclui em si mesmo, pois consideramos que outras pesquisas devam ser realizadas para acompanhar os demais anos letivos que se sucederão 
nas escolas que atuam com a modalide Ensino Médio de Tempo Integral e com o Programa Escola do Novo Tempo.

\section{REFERÊNCIAS}

ALONSO, M. 0 papel do diretor na administração escolar. 6. ed. Rio de Janeiro: Bertrand Brasil, 1988.

ARIQUEMES. Prefeitura Municipal de Ariquemes. Lei n. 1.217, de 21 de junho de 2006. Institui o Projeto Burareiro - Escola de Tempo Integral de Ensino Fundamental do Município de Ariquemes e dá outras providências. Palácio do Cacau, Ariquemes, RO, 21 jun. 2006.

BARDIN, L. Análise de conteúdo. São Paulo: Edições 70, 201.

BOGDAN, R. C.; BIKLEN, S. K. Investigação qualitativa em educação. Porto, Portugal: Porto Editora, 1994.

BRASIL. Decreto n. 7.083, de 27 de janeiro de 2010. Dispõe sobre o programa Mais Educação. Diário Oficial da União, Brasilia, DF, 28 jan. 2010. Disponivel em: http://www.planalto.gov.br/ccivil_03/_ ato2007-2010/2010/decreto/d7083.htm. Acesso em: 23 abr. 2016.

BRASIL. Lei n. 13.005, de 25 de junho de 2014. Dispõe sobre o Plano Nacional de Educação - PNE e dá outras providências. Diário Oficial da União, Brasília, DF, 26 jun. 2014. Disponível em: http://www. planalto.gov.br/ccivil_03/_ato2011-2014/2014/lei/113005.htm. Acesso em: 17 ago. 2016.

BRASIL. Lei n. 13.415, de 16 de fevereiro de 2017. Altera as Leis n ․ 9.394, de 20 de dezembro de 1996, [...] e institui a Política de Fomento à Implementação de Escolas de Ensino Médio em Tempo Integral. Diário Oficial da União, Brasilia, DF, 17 fev. 2017. Disponível em: http://www.planalto.gov.br/ccivil_03/_ ato2015-2018/2017/Lei/L13415.htm. Acesso em: 7 maio 2020.

BRASIL. Ministério da Educação. Portaria Normativa Interministerial n. 17, de 24 de abril de 2007. Dispõe sobre o Programa Mais Educação. Diário Oficial da União, Brasília, DF, 26 abr. 2007. Disponível em: http://portal.mec.gov.br/arquivos/pdf/mais_educacao.pdf. Acesso em: 16 ago. 2016.

BRASIL. Portaria n. 1.145, 10 de outubro de 2016, institui o Programa de Fomento à Implementação de Escolas em Tempo Integral, criada pela Medida Provisória no 746, de 22 de setembro de 2016. Diário Oficial da União, Brasília, DF, 11 out. 2016. Disponivel em: http://portal.mec.gov.br/docman/outubro-2016-pdf/49121-port-1145-11out-pdf/file. Acesso em: 7 mai. 2020. 
BRASIL. Ministério da Educação. Resolução n 4, de 17 de dezembro de 2018. Institui a Base Nacional Comum Curricular na Etapa do Ensino Médio (BNCC-EM), como etapa final da Educação Básica, nos termos do artigo 35 da LDB, completando o conjunto constituído pela BNCC da Educação Infantil e do Ensino Fundamental, com base na Resolução CNE/CP n ${ }^{\circ}$ 2/2017, fundamentada no Parecer CNE/ CP n` 15/2017. Diário Oficial da União, Brasilia, DF 18 de dez. 2018. Disponivel em: http://portal.mec.gov. $\mathrm{br} /$ conselho-nacional-de-educacao/base-nacional-comum-curricular-bncc-etapa-ensino-medio . Acesso em: 20 ago. 2020.

CARVALHO, F. R. S. Educação integral no município de Ariquemes: uma leitura curricular do Programa Escola do Novo Tempo - Ensino Médio em Tempo Integral. 2018. 182 f. Dissertação (Mestrado em educação) - Universidade Federal de Rondônia, Porto Velho, 2018.

CHIAVENATO, I. Gestão de Pessoas. 2. ed. São Paulo: Campus, 2005.

COSTA, A. C. G. 0 protagonismo juvenil passo a passo: um guia para o educador. Belo Horizonte: Universidade, 2001.

FRUTUOSO, C. As políticas de educação integral em Ariquemes-Rondônia: uma análise do projeto Burareiro de educação integral e do programa mais educação. 2014. 116 f. Dissertação (Mestrado em educação) - Universidade Federal de Rondônia, Porto Velho, 2014.

GIL, A. C. Como elaborar projetos de pesquisa. 6. ed. São Paulo: Atlas, 2017.

GOMES, D. D. MBA Educação: a gestão estratégica na escola que aprende. Rio de Janeiro: Qualitymark, 2009.

IBGE. Censo 2018. População. Brasilia, DF: IBGE, 2018. Disponível em: https://cidades.ibge.gov.br/brasil/ ro/panorama. Acesso em: 5 mar. 2019.

LIBÂNEO, J. C. Organização e gestão da escola: teoria e prática. 6. ed. Goiânia: MF Livros, 2015.

LIMA, L. C. V. Organização Escolar e democracia radical: Paulo Freire e a governação democrática da escola pública. São Paulo: Cortez, 2000.

LÜCK, H. et al. A escola participativa: o trabalho do gestor escolar. 10. ed. Petrópolis, RJ: Vozes, 2012.

MACIEL, A. C.; BRAGA, R. M. Projeto Burareiro: politecnia e educação integral à luz da pedagogia histórico-crítica. In: SANTOS, N. Alinhavos em ciências humanas. Porto Velho: EDUFR0, 2007. p. 59-74.

MACIEL, A. C.; JACOMELI, M. R. M.; BRASILEIRO, T. S. A. Fundamentos da educação integral politécnica: da teoria à prática. Educação \& Sociedade, Campinas, SP, v. 38, n. 139, p. 473-488, abr./jun. 2017.

MACIEL, A. C.; SILVA, C. A.; FRUTUOSO, C. 0 conceito de educação integral e as possibilidades da educação integral politécnica em Manaus. Práxis Educacional, Vitória da Conquista, BA, v. 15, n. 32, p. 174-204, abr./jun. 2019. 
RIBEIRO, J. Q. Ensaio de uma teoria da Administração Escolar. São Paulo: Saraiva, 1986.

RONDÔNIA. Governo do Estado de Rondônia. Lei Complementar n. 940, de 10 de abril de 2017, institui o Programa Escola do Novo Tempo, no âmbito do Estado de Rondônia, vinculado à Secretaria de Estado da Educação - SEDUC e dá outras providências. Disponivel em: http://ditel.casacivil.ro.gov.br/COTEL/ Livros/Files/LC940.pdf. Acesso em 7 mai. 2020.

RONDÔNIA. Governo do Estado de Rondônia. Lei n. 3.565, de 3 junho 2015. Institui o Plano Estadual de Educação de Rondônia - PEE/RO. Rondônia, 3 jun. 2015. Disponivel em: http://www.seduc.ro.gov.br/ cee/index.php/conselho.html.

RONDÔNIA. Governo do Estado de Rondônia. Programa Escola do Novo Tempo de educação integral inicia ano letivo em Rondônia. Rondônia: Secretaria do Estado da Educação, 26 fev. 2019.

RONDÔNIA. Secretaria de Estado da Educação. Resolução n 1.228/18. Aprova o Projeto Escolas de Ensino Médio em Tempo Integral do Programa Escola do Novo Tempo. Diário Oficial do Estado, Porto Velho, 2018.

SANDER, B. Administração da Educação no Brasil: genealogia do conhecimento. Brasilia: Liber Livro, 2007.

SANDER, B. Políticas públicas e gestão democrática da educação. Brasília: Liber Livro Editora, 2005.

VIEIRA, A. T.; ALMEIDA, M. E. B.; ALONSO, M. Gestão Educacional e Tecnologia. São Paulo: Avercamp, 2003.

Endereço para correspondência: Avenida Presidente Dutra, 2965, Olaria, 76801-058, Porto Velho, Rondônia, Brasil; castro@unir.br 
